\title{
Mandibular Reconstruction Using the Free Vascularized Fibula Graft: An Overview of Different Modifications
}

\author{
George Kokosis ${ }^{1}$, Robin Schmitz ${ }^{2}$, David B. Powers ${ }^{1}$, Detlev Erdmann ${ }^{1}$ \\ ${ }^{1}$ Division of Plastic, Reconstructive, Maxillofacial and Oral Surgery, Duke University Medical Center, Durham, NC, USA; ${ }^{2}$ Department of \\ General, Visceral and Transplantation Surgery, University of Heidelberg, Heidelberg, Germany
}

The reconstruction of the mandible is a complex procedure because various cosmetic as well as functional challenges must be addressed, including mastication and oral competence. Many surgical techniques have been described to address these challenges, including nonvascularized bone grafts, vascularized bone grafts, and approaches related to tissue engineering. This review summarizes different modifications of the free vascularized fibula graft, which, since its introduction by Hidalgo in 1989, has become the first option for mandibular reconstruction. The fibula free flap can undergo various modifications according to the individual requirements of a particular reconstruction. Osteocutaneous flaps can be harvested for reconstruction of composite defects. 'Double-barreling' of the fibula can, for instance, enable enhanced aesthetic and functional results, as well as immediate one-stage osseointegrated dental implantation. Recently described preoperative virtual surgery planning to facilitate neomandible remodeling could guarantee good results. To conclude, the free fibula bone graft can currently be regarded as the "gold standard" for mandibular reconstruction in case of composite (inside and outside) oral cavity defects as well as a way of enabling the performance of one-stage dental implantation.

Keywords Mandibular reconstruction / Fibula / Microsurgery
Correspondence: George Kokosis Division of Plastic, Reconstructive, Maxillofacial and Oral Surgery, Duke University Medical Center, Box 3181, Durham, NC 27710, USA

Tel: +1-919-684-3320

Fax: +1-919-681-2670

E-mail: George.kokosis@duke.edu

No potential conflict of interest relevant to this article was reported.

Received: 20 Nov $2015 \bullet$ Revised: 22 Dec $2015 \bullet$ Accepted: 31 Dec 2015

pISSN: 2234-6163 • elSSN: 2234-6171 • http://dx.doi.org/10.5999/aps.2016.43.1.3 • Arch Plast Surg 2016;43:3-9

\section{INTRODUCTION}

The reconstruction of the mandible is a complex procedure and continues to be a challenge in reconstructive craniomaxillofacial plastic surgery. Indications for mandibular reconstruction are versatile, and include oncologic resections, traumatic injuries, and osteoradionecrosis $[1,2]$. The mandible serves several important functions in the head and neck. The ultimate goal is restoration of both form and function, necessitating the evaluation of appearance, mastication, deglutition, speech, and oral com- petence. This can be achieved through a variety of surgical techniques, mainly non-vascularized and vascularized grafts. Nonvascularized bone grafts (NVBGs) may be suitable in specific circumstances, like delayed reconstructions of small traumatic bony defects. They provide a framework for creeping substitution. Yet the lack of blood supply results in slow and incomplete healing, as well as increased rates of infection, non-union, and fracture $[3,4]$. They are also prone to osteoradionecrosis in conjunction with radiation therapy [5].

The advent of microvascular surgery has revolutionized man- 
dibular reconstruction, especially after cancer treatment utilizing radiation. Vascularized bone grafts (VBGs) contain an intrinsic blood supply that adds the biological advantage of shortened union time. Outcomes from free VBGs, most notably free fibula grafts, have proved markedly superior to non-vascularized options, including reconstruction plates and bone grafts, with defects of the mandible exceeding $6 \mathrm{~cm}$ in length and traversing the parasymphyseal and/or anterior border regions $[3,4]$.

Direct comparisons of NVBGs and vascularized bone flaps (VBFs) have shown superiority of the latter in terms of bony union (69\% for NVBGs vs. $96 \%$ of VBFs) [3] as well as superior functional and aesthetic scores for diet, speech, and midline symmetry [6]. Superiority of VBGs compared to NVBGs increases significantly in case of mandibular defects greater than $6 \mathrm{~cm}$ or previously irradiated tissue [3]. Available options for VBGs are the fibula, radial forearm, scapula, and iliac crest [7-10], with the fibula flap being the most popular for mandibular reconstruction.

In this review, the authors present different variations of the free vascularized fibula graft, which could serve as the treatment of choice for mandibular reconstruction.

\section{FIBULA FLAP}

The use of free vascularized fibula has become the "gold standard" for mandibular reconstruction since its introduction by Hidalgo [11] in 1989, due to various advantages over other VBGs. First, the fibula graft offers a good length of dense cortical bone, up to $25 \mathrm{~cm}$ in adults, as well as a long pedicle based on the peroneal artery for the reconstruction of long bony defects. Since the fibula graft was first described, many surgeons have adopted and ultimately optimized the technique. Today, multiple modifications exist, each one developed to fit in a specific individualized defect scenario.

\section{Bone-only and osteoseptocutaneous flap}

A few circumstances exist in which there is no associated soft tissue damage and an osseous flap only is sufficient to bridge the defect. Composite tissue loss is usually more extensive, and the versatility of the fibula flap comes into play.

The fibula graft may provide skin islands, up to $25 \mathrm{~cm}$ long and $14 \mathrm{~cm}$ wide, suitable for reconstruction of associated soft tissue defects (Fig. 1). Chen and Yan [12] were the first to describe the osteocutaneous fibula flap in 1983. Multiple skin islands can be harvested with the fibula graft, including those based on septocutaneous as well as on musculocutaneous peroneal perforators supplying an osteomyocutaneous flap $[13,14]$. The most reliable septocutaneous perforators are located in the middle and distal third of the fibula [15]. Modifications have been
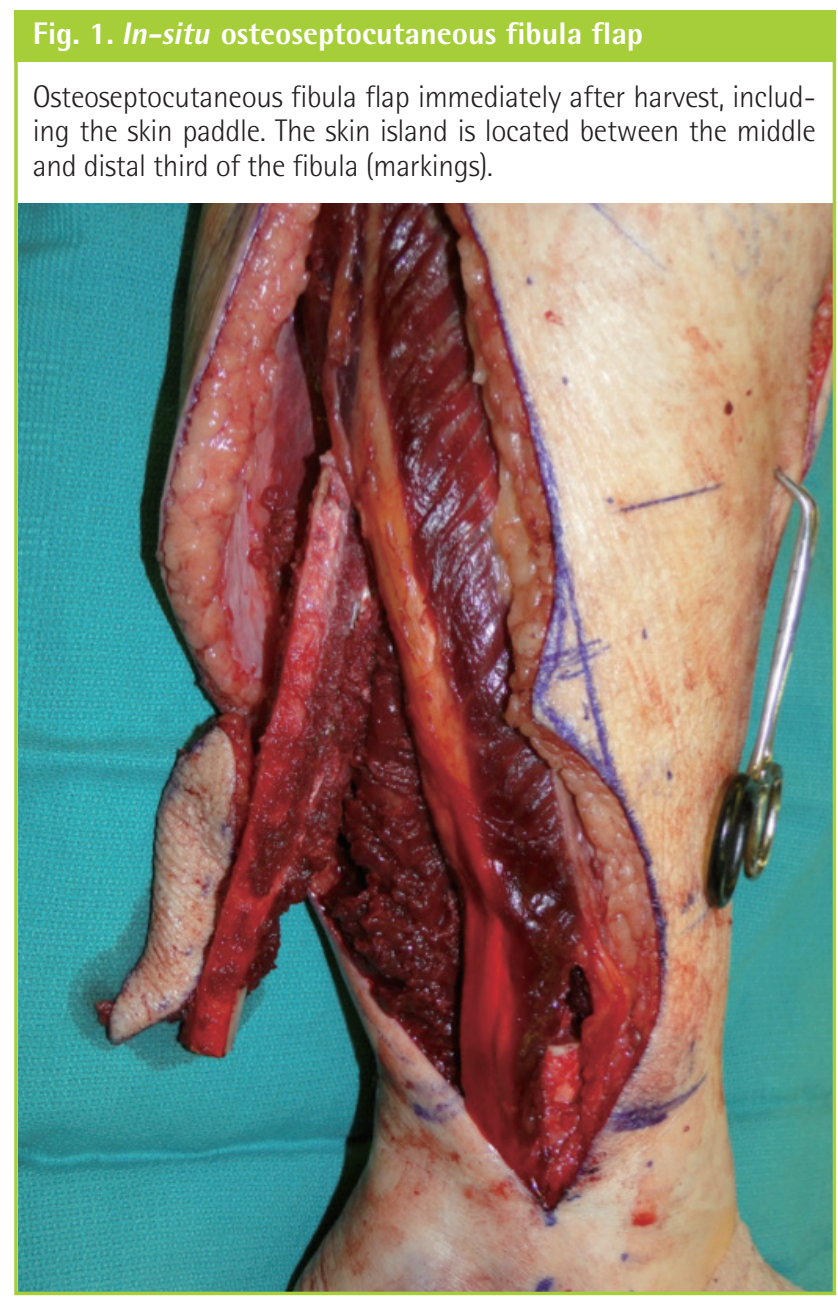

developed that include parts of the soleus or peroneus longus. Most recently, a second skin island based on proximal perforators off the peroneal artery present in $90 \%$ of the cases was described [16]. Thus, this graft provides convenient tissue for simultaneous reconstruction of bony and soft tissue defects inside as well as outside the oral cavity, bringing viable tissue to a mostly irradiated and contaminated field, with the lowest complication rate among osteocutaneous flaps [17]. Limitations of the extent of the skin paddle harvested with the fibula graft have been overcome with the previously described double-skin paddle fibula free flaps based on septocutaneous, intramuscular, and soleus perforators (Fig. 2) [18,19].

\section{Double barreling}

The height discrepancy between the native mandible and the transplanted fibula can be a disadvantage of this approach, especially at the anterior segment, which significantly complicates prosthodontic reconstruction of the mandible. The average height of the native mandible, including the dentition, is generally in excess of $3-4 \mathrm{~cm}$. The average height of the fibula is usually 


\section{Fig. 2. Double-skin island osteoseptoctaneous fibula free flap}

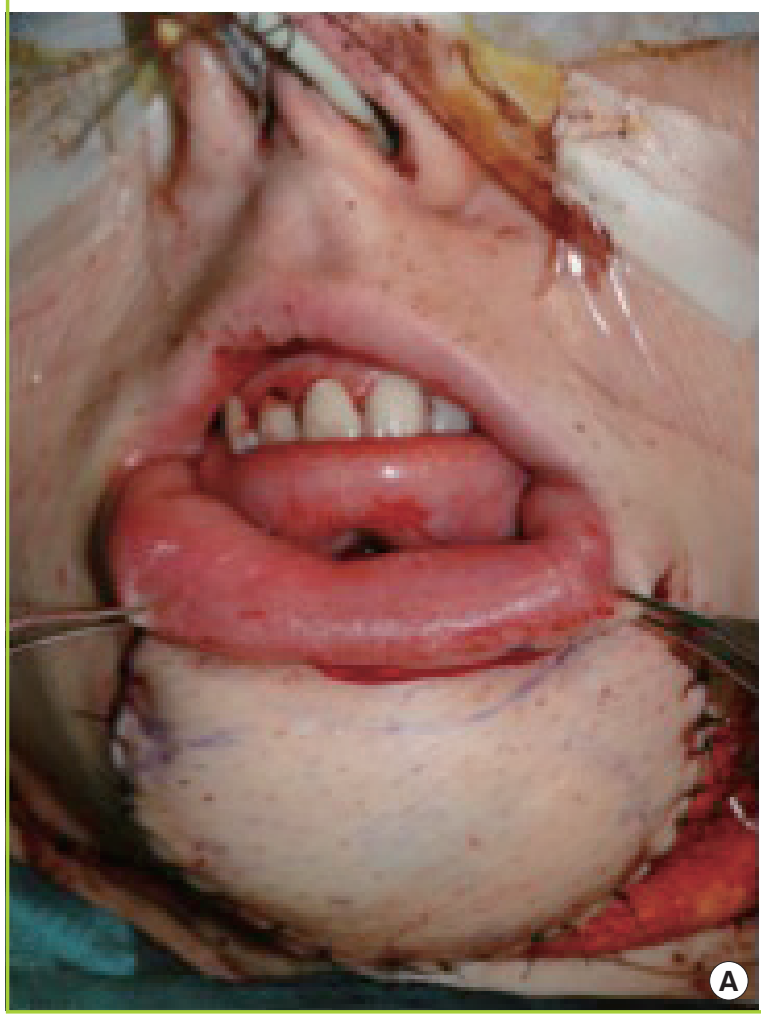

In this patient after major mandibular resection for osteosarcoma, the doubleskin island osteoseptocutaneous fibula free flap is used for simultaneous reconstruction of a soft tissue defect externally (A) and intraorally (B). The photograph depicts the immediate reconstructive result at the end of the procedure.

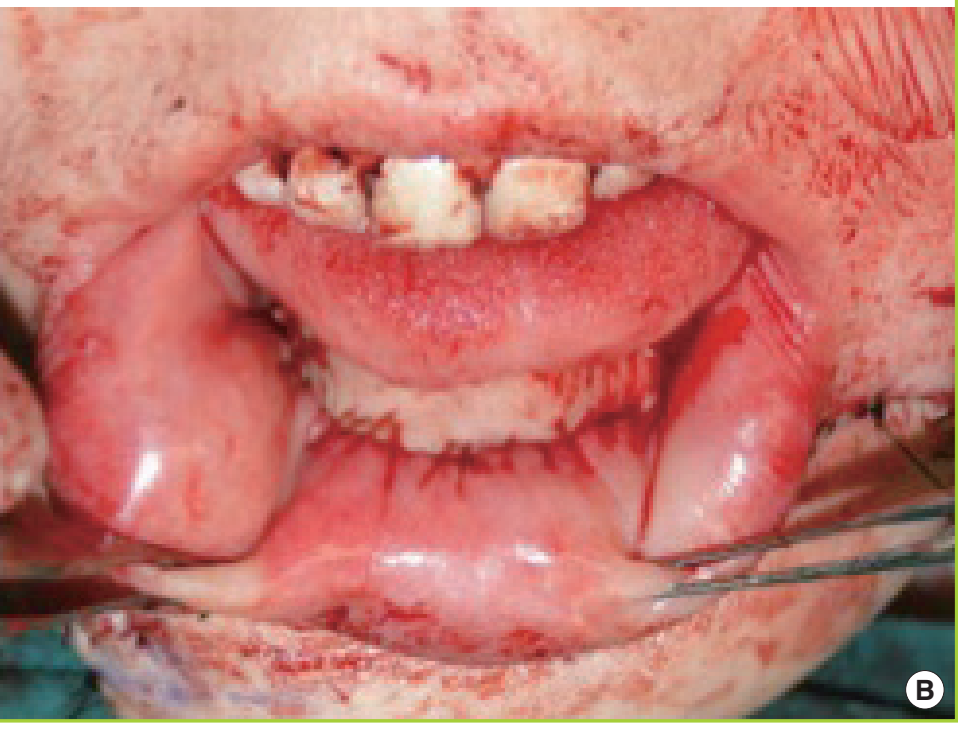

10-12 mm, which presents a reconstructive dilemma, as this height is inadequate to allow for placement of dental implants that can be restored in a functional setting. 'Double-barreling' of the fibula, a technique that involves osteotomies and folding over the fibula graft to create equal struts, while preserving the blood supply throughout the graft, was first recommended by Horiuchi et al. [20] in 1995. A double-barrel fibula flap conveniently matches the height of the mandible of $3-4 \mathrm{~cm}$, leading to better aesthetic and functional results and enabling a onestage procedure with immediate osseointegrated dental implantation (Fig. 3) [21,22]. In terms of dental implantation, the vertical distraction technique has been described to expand the neomandible up to $15 \mathrm{~mm}$ to allow a delayed osseointegrated dental implantation after 4-6 months in a three-stage procedure [2]. Most recently published data have shown a increased complexity and frequency of complications with the vertical distraction technique compared to double-barreled fibula grafts and therefore recommend the use of double-barreled fibula grafts for osseointegrated dental implants [23]. Depending on the reconstructive purpose, the fibula can also be partially double-barreled [2]. A 98\% flap survival and good aesthetic and functional outcomes have been reported [24].

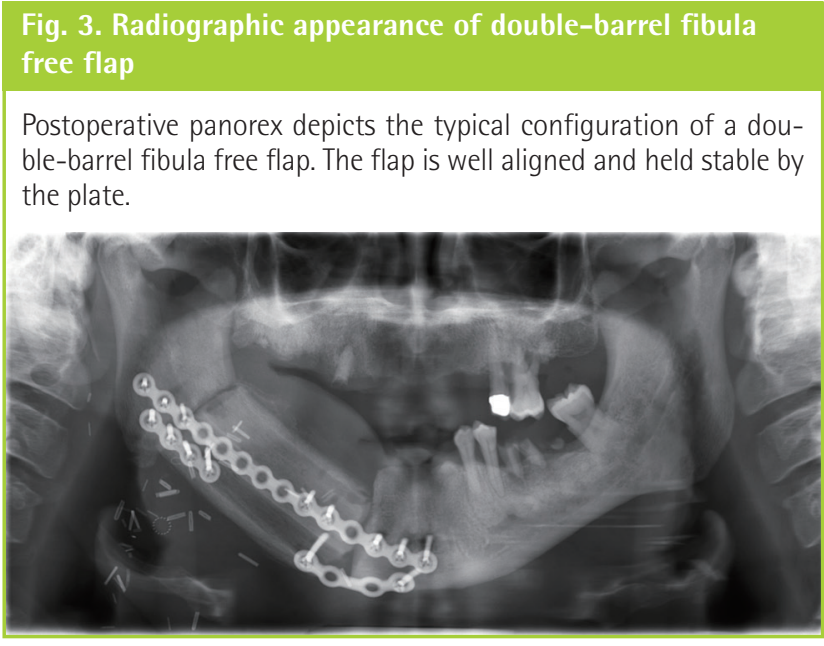

\section{Pre-plating and osteotomies}

To recreate the anatomic form of the mandible, especially the contour of the anterior portion, the fibula has to be divided into several segments using a closed wedge osteotomy technique with potentially multiple osteotomies. The number of osteotomies should be kept to a minimum to preserve reliable segmental periosteal circulation [25]. The accurate restoration of the neomandible is crucial due to sufficient occlusion and acceptable aesthetic results. The contour of the neomandible will be defined principally by the curve of a reconstruction plate formed 


\section{Fig. 4. Preparation of three-dimensional models of fibula grafts prior to surgery}

(A) Prefabricated plate bend on a three-dimensional model of the neomandible. (B) Cutting guide for in situ donor-site osteotomies. (C) In situ construct of prefabricated plate and osteotomized fibula.
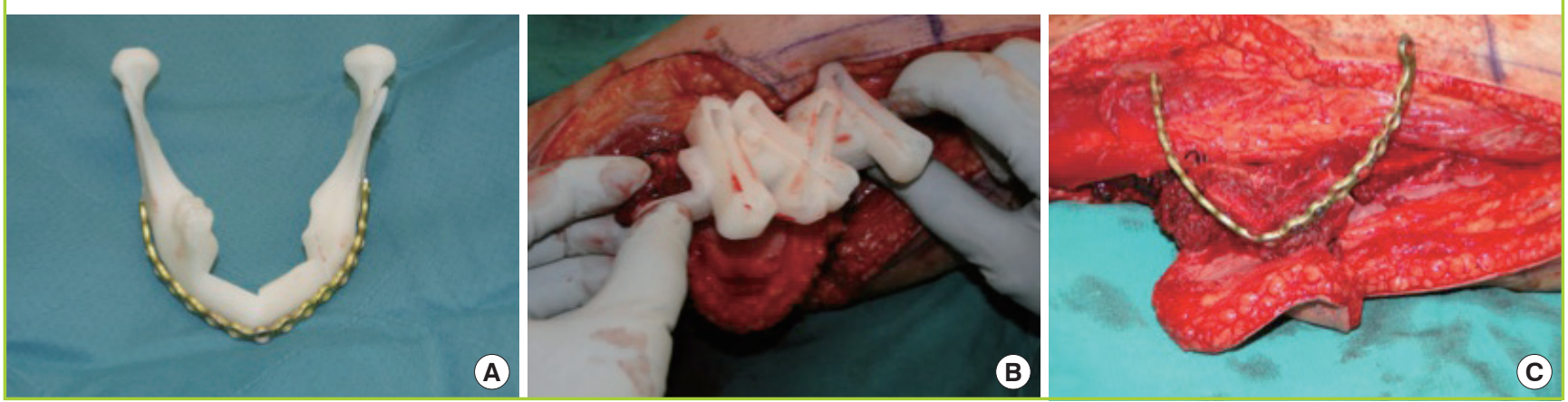

prior to the surgery or during the surgery using a no-touch technique along the specimen. Another technique includes pre-plating of the mandible prior to the resection. Different variations of pre-plating are described depending on the tumor spread [26]. The stereolithographic model completes this technique involving preplating, templating, and insetting of the mandible with convincing results with regard to shape and function [27].

\section{Prefabricated plates and cutting systems - three- dimensional approach}

As described before, sculpting the fibula graft is a critical step during restoration of the mandibular shape. The evolution of technology has introduced three-dimensional (3D) approaches to virtual surgical planning by preparation of 3D models of fibula grafts prior to surgery. Stereolithographic models of the mandible and the fibula can be obtained from computer tomography scan data preoperatively [28]. Subsequently, plates can be bent according to the model to increase the accuracy and decrease the duration of surgery by preplanning each step of the operation including the osteotomies on the mandible and the fibula by use of staged cutting guides (Fig. 4) [29]. Thus, computer-assisted mandibular reconstruction (CAMR) has increased preoperative planning accuracy, resulting in greater surgical precision and reduction of surgical duration [30]. However, these models are expensive, require a strict realization of the planned intervention, and are not easily adaptable to an aberrant surgical approach [31].

\section{Future directions}

Utilization of microsurgery in management of the mandibular reconstruction, even though associated with adequate outcomes and low donor-site morbidity [32], it remains challenging. Future strategies include tissue engineering approaches utilizing collagen-based scaffolds combined with bone marrow-derived stromal cells and growth factors $[5,33]$. Furthermore, particu- late cellular bone and marrow (PCBM) and platelet-rich plasma (PRP) has been shown to form microstructures of the cellular bone resembling those in normal mandibles [34]. Additionally, an off-label use of bone morphogenetic protein-2 (rhBMP-2) in a collagen carrier has been described as a new alternative to various types of autogenous bone grafting procedures $[35,36]$. Nevertheless, none of these approaches can yet be considered established as standard in craniomaxillofacial reconstructive surgery.

\section{DISCUSSION}

The reconstruction of mandibular defects is complex due to the need to address both functional and aesthetic objectives. This review has noted that reconstruction with a free fibula bone graft has been shown to produce superior patient outcomes over NVBGs $[3,4]$. Nevertheless, it is also one of the most challenging procedures from the standpoint of craniomaxillofacial surgery. For this reason, NVBGs may be a reasonable alternative in selected cases, depending on the size of the bony and soft tissue defect $[37,38]$. Additionally, soft tissue flaps alone such as anterolateral thigh, gracilis, rectus, and latissimus dorsi have been successfully used in reconstruction of posterolateral defects [39, 40]. Tissue-engineered alternatives have also shown promise but still need more comprehensive clinical testing. In the case of additional soft tissue defects, a fibula graft can be harvested with various reliable skin paddles [1], which enable a one-stage reconstructive procedure of composite mandibular defects [4143]. Several modifications of skin paddles have been described, including a chimeric double-skin paddle [18] for simultaneous reconstruction of intra- and extraoral defects [44]. Especially in such complex defects, the free fibula graft has outstanding importance. Another advantage of the free vascularized fibula graft is the ability to have two teams working simultaneously with the patient in the supine position by reducing operating time, which is associated with reduced blood loss and lower rates of infec- 
tion [45]. Additionally, the blood supply can be monitored postoperatively with an implantable Cook-Swartz Doppler probe, since the peroneal artery remains sizeable, enabling the recognition of vascular compromise early, which in turn results in an overall flap success rate of $98.1 \%[46,47]$. The donor site morbidity of the free vascularized fibula graft is consistently acceptable among different studies, and is mostly avoidable with careful planning and appropriate technique [48-50].

One disadvantage of the free fibula graft is the height discrepancy between the native mandible and the transplanted fibula, especially at the anterior segment. The 'double-barreling' of the fibula to create equal struts is a useful modification with good aesthetic and functional outcomes [24]. Partially double-barreled grafts, as needed for aesthetic improvements, have also been reported, and a commonly used modification [2]. The 'double-barreling' of the fibula enables immediate osseointegrated dental implantation, obtaining better results and lower complication rates compared to vertical distraction devices [23]. Levine et al. [51] even published three cases of total mandibular reconstruction in a single stage procedure with immediate dental implantation. Preoperative virtual surgery planning using 3D technology has shown convincing improvements in postoperative outcomes, including a reduced operation duration and increased functional as well as aesthetic results, and should be considered, especially in complex defects [52]. However, as discussed before, these models are expensive and have not become an integral part of the surgical approach [31].

\section{REFERENCES}

1. Erdmann D, Giessler GA, Bergquist GE, et al. Free fibula transfer: analysis of 76 consecutive microsurgical procedures and review of the literature. Chirurg 2004;75:799-809.

2. Wallace CG, Chang YM, Tsai CY, et al. Harnessing the potential of the free fibula osteoseptocutaneous flap in mandible reconstruction. Plast Reconstr Surg 2010;125:305-14.

3. Foster RD, Anthony JP, Sharma A, et al. Vascularized bone flaps versus nonvascularized bone grafts for mandibular reconstruction: an outcome analysis of primary bony union and endosseous implant success. Head Neck 1999;21:6671.

4. Pogrel MA, Podlesh S, Anthony JP, et al. A comparison of vascularized and nonvascularized bone grafts for reconstruction of mandibular continuity defects. J Oral Maxillofac Surg 1997;55:1200-6.

5. Chim H, Salgado CJ, Mardini S, et al. Reconstruction of mandibular defects. Semin Plast Surg 2010;24:188-97.

6. King TW, Gallas MT, Robb GL, et al. Aesthetic and func- tional outcomes using osseous or soft-tissue free flaps. J Reconstr Microsurg 2002;18:365-71.

7. Taylor GI, Townsend P, Corlett R. Superiority of the deep circumflex iliac vessels as the supply for free groin flaps. Plast Reconstr Surg 1979;64:595-604.

8. Soutar DS, Scheker LR, Tanner NS, et al. The radial forearm flap: a versatile method for intra-oral reconstruction. $\mathrm{Br} \mathrm{J}$ Plast Surg 1983;36:1-8.

9. Swartz WM, Banis JC, Newton ED, et al. The osteocutaneous scapular flap for mandibular and maxillary reconstruction. Plast Reconstr Surg 1986; 77:530-45.

10. Taylor GI, Miller GD, Ham FJ. The free vascularized bone graft: a clinical extension of microvascular techniques. Plast Reconstr Surg 1975;55:533-44.

11. Hidalgo DA. Fibula free flap: a new method of mandible reconstruction. Plast Reconstr Surg 1989;84:71-9.

12. Chen ZW, Yan W. The study and clinical application of the osteocutaneous flap of fibula. Microsurgery 1983;4:11-6.

13. Daya M. Peroneal artery perforator chimeric flap: changing the perspective in free fibula flap use in complex oromandibular reconstruction.J Reconstr Microsurg 2008;24:413-8.

14. Cheng MH, Saint-Cyr M, Ali RS, et al. Osteomyocutaneous peroneal artery-based combined flap for reconstruction of composite and en bloc mandibular defects. Head Neck 2009; 31:361-70.

15. Heitmann C, Khan FN, Levin LS. Vasculature of the peroneal artery: an anatomic study focused on the perforator vessels. J Reconstr Microsurg 2003;19:157-62.

16. Potter JK, Lee MR, Oxford L, et al. Proximal peroneal perforator in dual-skin paddle configuration of fibula free flap for composite oral reconstruction. Plast Reconstr Surg 2014; 133:1485-92.

17. Hayden RE, Mullin DP, Patel AK. Reconstruction of the segmental mandibular defect: current state of the art. Curr Opin Otolaryngol Head Neck Surg 2012;20:231-6.

18. Leclere FM, Bosc R, Temam S, et al. Reconstruction of large mandibulofacial defects with the composed double skin paddle fibula free flap: a review of 32 procedures. Laryngoscope 2014;124:1336-43.

19. Nakajima H, Fujino T, Adachi S. A new concept of vascular supply to the skin and classification of skin flaps according to their vascularization. Ann Plast Surg 1986;16:1-19.

20. Horiuchi K, Hattori A, Inada I, et al. Mandibular reconstruction using the double barrel fibular graft. Microsurgery 1995; 16:450-4.

21. Chang YM, Tsai CY, Wei FC. One-stage, double-barrel fibula osteoseptocutaneous flap and immediate dental implants for functional and aesthetic reconstruction of segmental 
mandibular defects. Plast Reconstr Surg 2008;122:143-5.

22. He Y, Zhang ZY, Zhu HG, et al. Double-barrel fibula vascularized free flap with dental rehabilitation for mandibular reconstruction. J Oral Maxillofac Surg 2011;69:2663-9.

23. Chang YM, Wallace CG, Hsu YM, et al. Outcome of osseointegrated dental implants in double-barrel and vertically distracted fibula osteoseptocutaneous free flaps for segmental mandibular defect reconstruction. Plast Reconstr Surg 2014;134:1033-43.

24. Shen Y, Guo XH, Sun J, et al. Double-barrel vascularised fibula graft in mandibular reconstruction: a 10-year experience with an algorithm. J Plast Reconstr Aesthet Surg 2013;66: 364-71.

25. Strackee SD, Kroon FH, Jaspers JE, et al. Modeling a fibula transplant in mandibular reconstructions: evaluation of the effects of a minimal number of osteotomies on the contour of the jaw. Plast Reconstr Surg 2001;108:1915-21.

26. Marchetti C, Bianchi A, Mazzoni S, et al. Oromandibular reconstruction using a fibula osteocutaneous free flap: four different "preplating” techniques. Plast Reconstr Surg 2006; 118:643-51.

27. Pellini R, Mercante G, Spriano G. Step-by-step mandibular reconstruction with free fibula flap modelling. Acta Otorhinolaryngol Ital 2012;32:405-9.

28. Yeung RW, Samman N, Cheung LK, et al. Stereomodel-assisted fibula flap harvest and mandibular reconstruction. J Oral Maxillofac Surg 2007;65:1128-34.

29. Hirsch DL, Garfein ES, Christensen AM, et al. Use of computer-aided design and computer-aided manufacturing to produce orthognathically ideal surgical outcomes: a paradigm shift in head and neck reconstruction. J Oral Maxillofac Surg 2009;67:2115-22.

30. Succo G, Berrone M, Battiston B, et al. Step-by-step surgical technique for mandibular reconstruction with fibular free flap: application of digital technology in virtual surgical planning. Eur Arch Otorhinolaryngol 2015;272:1491-501.

31. Moro A, Cannas R, Boniello R, et al. Techniques on modeling the vascularized free fibula flap in mandibular reconstruction. J Craniofac Surg 2009;20:1571-3.

32. Ling XF, Peng X. What is the price to pay for a free fibula flap? A systematic review of donor-site morbidity following free fibula flap surgery. Plast Reconstr Surg 2012;129:65774.

33. Seto I, Marukawa E, Asahina I. Mandibular reconstruction using a combination graft of rhBMP-2 with bone marrow cells expanded in vitro. Plast Reconstr Surg 2006;117:902-8.

34. Matsuo A, Chiba H, Takahashi $\mathrm{H}$, et al. Bone quality of mandibles reconstructed with particulate cellular bone and mar- row, and platelet-rich plasma. J Craniomaxillofac Surg 2011; 39:628-32.

35. Herford AS, Boyne PJ. Reconstruction of mandibular continuity defects with bone morphogenetic protein-2 (rhBMP-2). J Oral Maxillofac Surg 2008;66:616-24.

36. Carter TG, Brar PS, Tolas A, et al. Off-label use of recombinant human bone morphogenetic protein-2 (rhBMP-2) for reconstruction of mandibular bone defects in humans. J Oral Maxillofac Surg 2008;66:1417-25.

37. van Gemert JT, van Es RJ, Van Cann EM, et al. Nonvascularized bone grafts for segmental reconstruction of the mandible: a reappraisal. J Oral Maxillofac Surg 2009;67:144652.

38. Gadre PK, Ramanojam S, Patankar A, et al. Nonvascularized bone grafting for mandibular reconstruction: myth or reality? J Craniofac Surg 2011;22:1727-35.

39. Hanasono MM, Zevallos JP, Skoracki RJ, et al. A prospective analysis of bony versus soft-tissue reconstruction for posterior mandibular defects. Plast Reconstr Surg 2010;125:141321.

40. Mosahebi A, Chaudhry A, McCarthy CM, et al. Reconstruction of extensive composite posterolateral mandibular defects using nonosseous free tissue transfer. Plast Reconstr Surg 2009; 124:1571-7.

41. Wei FC, Seah CS, Tsai YC, et al. Fibula osteoseptocutaneous flap for reconstruction of composite mandibular defects. Plast Reconstr Surg 1994;93:294-304.

42. Minami A, Usui M, Ogino T, et al. Simultaneous reconstruction of bone and skin defects by free fibular graft with a skin flap. Microsurgery 1986; 7:38-45.

43. van Twisk R, Pavlov PW, Sonneveld J. Reconstruction of bone and soft tissue defects with free fibula transfer. Ann Plast Surg 1988;21:555-8.

44. Loeffelbein DJ, Holzle F, Wolff KD. Double-skin paddle perforator flap from the lateral lower leg for reconstruction of through-and-through cheek defect: a report of two cases. Int J Oral Maxillofac Surg 2006;35:1016-20.

45. Rosenberg AJ, Van Cann EM, van der Bilt A, et al. A prospective study on prognostic factors for free-flap reconstructions of head and neck defects. Int J Oral Maxillofac Surg 2009;38:666-70.

46. Guillemaud JP, Seikaly H, Cote D, et al. The implantable Cook-Swartz Doppler probe for postoperative monitoring in head and neck free flap reconstruction. Arch Otolaryngol Head Neck Surg 2008; 134:729-34.

47. Kind GM, Buntic RF, Buncke GM, et al. The effect of an implantable Doppler probe on the salvage of microvascular tissue transplants. Plast Reconstr Surg 1998;101:1268-73. 
48. Hidalgo DA, Pusic AL. Free-flap mandibular reconstruction: a 10-year follow-up study. Plast Reconstr Surg 2002;110: 438-49.

49. Anthony JP, Rawnsley JD, Benhaim P, et al. Donor leg morbidity and function after fibula free flap mandible reconstruction. Plast Reconstr Surg 1995;96:146-52.

50. Bodde EW, de Visser E, Duysens JE, et al. Donor-site morbidity after free vascularized autogenous fibular transfer: subjective and quantitative analyses. Plast Reconstr Surg 2003;
$111: 2237-42$.

51. Levine JP, Bae JS, Soares M, et al. Jaw in a day: total maxillofacial reconstruction using digital technology. Plast Reconstr Surg 2013;131:1386-91.

52. Wang WH, Zhu J, Deng JY, et al. Three-dimensional virtual technology in reconstruction of mandibular defect including condyle using double-barrel vascularized fibula flap. J Craniomaxillofac Surg 2013;41:417-22. 